José RoBerto MORAles Piato ${ }^{1}$

Kátia Maciel Pincerato ${ }^{2}$

Vivian CaRLa da Silva GOMES ${ }^{3}$

Filomena Marino CaRVALHO ${ }^{4}$

Walter da Silva Pinheiro ${ }^{1}$

EDMUND ChadA BaracaT ${ }^{5}$

\section{Metástase oculta em linfonodo sentinela no câncer de mama em estádios iniciais}

\author{
Occult metastasis in sentinel lymph node in early-stage breast cancer
}

Artigos originais

Palavras-chave

Neoplasias da mama/cirurgia Biopsia de linfonodo sentinela Metástase neoplásica/diagnóstico Imunoistoquímica

Queratinas

Keywords

Breast neoplasms/surgery Sentinel lymph node biopsy Neoplasm metastasis/diagnosis Immunohistochemistry Keratins

\section{Resumo}

OBJETIVO: a identificação e biópsia do linfonodo sentinela (LS) no câncer de mama em estádio inicial vêm substituindo a dissecção axilar total. Neste estudo, será apresentada a técnica de processamento do LS, visando o diagnóstico de metástase oculta com base no exame histológico e imuno-histoquímico. MÉTODOS: entre os anos de 2002 e 2005, 266 linfonodos sentinelas foram dissecados em 170 pacientes com câncer de mama em estádio inicial. Foram incluídos apenas os linfonodos considerados negativos durante análise intra-operatória por citologia. Os linfonodos foram seccionados tranversalmente em quatro ou cinco fatias e incluídos em parafina. Em cada bloco de parafina, dois cortes histológicos com 4 um de espessura foram montados em lâminas para microscopia de luz e corados pela técnica da hematoxilina-eosina e imunoperoxidase (citoqueratina AE 1/AE3). RESULTADOS: a avaliação histológica convencional identificou metástase no LS de 22 pacientes (12,9\%). Em seis destas (3,5\%), o acometimento foi do tipo micrometástase. Já a metástase oculta diagnosticada exclusivamente pela imuno-histoquímica ocorreu em 16 pacientes $(9,4 \%)$. Em 11 destas $(6,5 \%)$ foram detectadas células tumorais isoladas e em cinco (2,9\%), micrometástases. CONCLUSÕES: a associação do exame histológico de parafina e imuno-histoquímica aumenta a capacidade de identificar metástase oculta no LS de pacientes com câncer de mama em estádios iniciais.

\section{Abstract}

PURPOSE: sentinel lymph node biopsy in early-stage breast cancer patients has been substituting the total axillary lymph node is presented dissection. The technique of processing the sentinel lymph node and the aim of this study was to investigate the efficacy of occult metastasis identification based on the standard histological and immunohistochemical examination. METHODS: between 2002 and 2005, 266 sentinel lymph nodes were harvested from axillary biopsy of 170 patients with early stage breast cancer. All lymph nodes were considered to be negative according to standard intra-operative cytological assessment. Lymph nodes were transversally sectioned in four or five slices and embedded in paraffin blocks. Two paraffin-embedded tissue sections with $4 \mu \mathrm{m}$ in thickness were mounted on glass slides and stained with hematoxylin-eosin and immunoperoxidase (cytokeratin AE 1 / AE3) techniques. RESULTS: standard histological examination identified metastasis in 22 patients (12.9\%) and micrometastatic disease was observed in six of these patients (3.5\%). The immunohistochemical examination identified metastatic disease in 16 patients (9.4\%). Among them, isolated tumor cells were observed in 11 (6.5\%) and micrometastases were identified in five (2.9\%). CONCLUSIONS: the association of the standard histological examination and immunohistochemical technique increases the chances of sentinel lymph node metastasis identification.
José Roberto Morales Piato Rua Rio de Janeiro, 67 - apto. 172 - Higienópolis CEP $01240-010$ - São Paulo/SP - Fone/Fax: (11) 3661.3462 E-mail: irpiato@uol.com.br

Recebido

18/1/08

Aceito com modificacões

26/8/08
Departamento de Obstetrícia e Ginecologia do Hospital das Clinicas da Faculdade de Medicina da Universidade de São Paulo USP - São Paulo (SP), Brasil.

' Doutor, Médico Assistente do Departamento de Obstetrícia e Ginecologia do Hospital das Clínicas da Faculdade de Medicina da Universidade de São Paulo - USP - São Paulo (SP), Brasil.

2 Doutora, Médica Assistente do Departamento de Anatomia Patológica do Hospital das Clínicas da Faculdade de Medicina da Universidade de São Paulo - USP - São Paulo (SP), Brasil; Laboratório Filomena Marino Carvalho - São Paulo (SP), Brasil.

${ }^{3}$ Acadêmica de Medicina da Faculdade de Medicina da Universidade de São Paulo -FMUSP - São Paulo (SP), Brasil.

${ }^{4}$ Livre-docente do Departamento de Anatomia Patológica do Hospital das Clínicas da Faculdade de Medicina da Universidade de São Paulo - USP - São Paulo (SP), Brasil; Laboratório Filomena Marino Carvalho - São Paulo (SP), Brasil.

5 Professor Titular do Departamento de Obstetrícia e Ginecologia do Hospital das Clínicas da Faculdade de Medicina da Universidade de São Paulo - USP - São Paulo (SP), Brasil. 


\section{Introdução}

A análise intra-operatória do linfonodo sentinela (LS) constitui um método com elevada acurácia para predição do estado linfonodal axilar em pacientes com câncer de mama em estádio inicial ${ }^{1-4}$. A biopsia do LS possibilita a preservação dos demais linfonodos da axila, reduzindo a morbidade pós-operatória no câncer de mama ${ }^{5,6}$.

O exame histopatológico rotineiro do LS, que consiste no estudo de um único corte histológico corado pela técnica de hematoxilina-eosina (HE), tem se mostrado incapaz para descartar ou confirmar a presença de metástase do tumor primário. Tal exame não apresenta a acurácia esperada, uma vez que em parte significativa dos casos em que o LS foi considerado livre existiam metástases, que foram detectadas por técnicas de exame imuno-histoquímico?

Metástases não diagnosticadas pelo exame histopatológico de rotina são denominadas ocultas. Duas variáveis desta forma de metástases são descritas: presença de células tumorais isoladas e micrometástases. As primeiras se constituem em células neoplásicas dispersas ou formando agrupamentos com até $0,2 \mathrm{~mm}$ de extensão e as micrometástases são definidas como agregados celulares com extensão entre 0,2 e $2 \mathrm{~mm}^{8}$.

No sentido de reduzir o número de falsos-negativos de metástases ocultas, há necessidade da realização sistemática de processamento anatomopatológico mais elaborado do LS, com cortes histológicos adicionais e estudo imuno-histoquímico. No entanto, não existe uma técnica padronizada para esta finalidade ${ }^{9-11}$. No presente estudo, é proposta técnica alternativa para estudo do LS e feita a avaliação de sua acurácia para identificação de metástases ocultas.

\section{Métodos}

O material do presente estudo foi constituído por 266 LS, oriundos de 170 pacientes acometidas por carcinoma invasivo de mama com tumores primários T1 e T2 e axilas clinicamente livres. A mediana da idade das pacientes foi de 54 anos, variando de 28 a 84 . Os dados relacionados com estado menopausal, estadiamento do tumor, tipo histológico, grau de diferenciação e padrões de expressão de receptores de estrógeno, progesterona e proteína HER2 são expostos na Tabela 1.

O teste do $\chi^{2}$ ou teste exato de Fisher foi utilizado para verificar a existência de associação entre os pacientes em que foram identificadas metástases e aqueles em que não foram, em relação às características clínico-patológicas.

O material da pesquisa foi colhido no período entre 2002 e 2005 e todos os linfonodos foram considerados negativos durante o exame citológico intra-operatório..
Dentre esses linfonodos, 84 foram processados no Serviço de Anatomia Patológica do Hospital das Clínicas da Faculdade de Medicina da Universidade de São Paulo (HC-FMUSP) e 182 em clínica privada. O processamento e a análise de todos os LS foram efetuados pelas mesmas patologistas e o trabalho foi iniciado após aprovação prévia no Comitê de Ética e Pesquisa do HC-FMUSP.

Cada linfonodo foi examinado a fresco no ato intraoperatório após ter sido fatiado transversalmente a cada 1,5 mm, com auxílio de bisturi de lâmina fria. Após estudo citológico de imprint intra-operatório, grupos de quatro ou cinco fatias de cada linfonodo foram incluídos em blocos separados de parafina e submetidos a cortes histológicos com $4 \mu \mathrm{m}$ de espessura e corados pela técnica de HE. Os blocos foram submetidos a cortes histológicos aprofundados adicionais a cada $50 \mu \mathrm{m}$ até esgotamento do material. No primeiro aprofundamento, correspondente a todos os cortes obtidos a cada $1,5 \mathrm{~mm}$, foram obtidos dois espécimes histológicos com aproximadamente $4 \mu \mathrm{m}$ de espessura, sendo que um deles foi corado pela técnica de HE e outro disposto em lâminas silanizadas para exame

Tabela 1 - Características clinicopatológicas de 170 pacientes com câncer de mama inicial submetidas à biópsia do linfonodo sentinela e resultado dos testes de associação

\begin{tabular}{|c|c|c|c|}
\hline Características & n (\%) & $\begin{array}{c}\text { Números de resultados } \\
\text { positivos (\%) }\end{array}$ & $\mathbf{p}$ \\
\hline \multicolumn{4}{|l|}{$\begin{array}{l}\text { Estado } \\
\text { menopausal }\end{array}$} \\
\hline Pré & $67(39,4)$ & & \\
\hline Pós & $103(60,6)$ & & \\
\hline \multicolumn{4}{|l|}{ Tamanho do tumor } \\
\hline$<\mathrm{l} \mathrm{cm}$ & $38(22,4)$ & $5(22,7)$ & $0,849^{\circ}$ \\
\hline $1-2 \mathrm{~cm}$ & $85(50,0)$ & $12(54,6)$ & \\
\hline$>2 \mathrm{~cm}$ & $47(27,6)$ & $5(22,7)$ & \\
\hline \multicolumn{4}{|l|}{ Tipo histológico } \\
\hline Ductal invasivo & $141(83,0)$ & $19(86,4)$ & $0,666^{\circ}$ \\
\hline Lobular invasivo & $22(12,9)$ & $2(9,1)$ & \\
\hline Outros tipos & $7(4,1)$ & $1(4,5)$ & \\
\hline \multicolumn{4}{|l|}{$\begin{array}{l}\text { Grau de } \\
\text { diferenciação }\end{array}$} \\
\hline Grau I & $38(22,4)$ & $4(18,2)$ & $0,879^{\circ}$ \\
\hline Grau II & $87(51,2)$ & $12(54,5)$ & \\
\hline Grau III & $45(26,4)$ & $6(27,3)$ & \\
\hline \multicolumn{4}{|l|}{$\begin{array}{l}\text { Receptor de } \\
\text { estrógeno }\end{array}$} \\
\hline Positivo* & $147(86,5)$ & $19(86,4)$ & $>0,999 \mathrm{~b}$ \\
\hline Negativo & $23(13,5)$ & $3(13,6)$ & \\
\hline \multicolumn{4}{|l|}{$\begin{array}{l}\text { Receptor de } \\
\text { progesterona }\end{array}$} \\
\hline Positivo* & $123(72,4)$ & $16(72,7)$ & $0,966^{\circ}$ \\
\hline Negativo & $47(27,6)$ & $6(27,3)$ & \\
\hline \multicolumn{4}{|l|}{ Proteina HER2 } \\
\hline Positivo & $28(16,5)$ & $4(18,2)$ & $0,763^{b}$ \\
\hline Negativo & $142(83,5)$ & $18(81,8)$ & \\
\hline
\end{tabular}

${ }^{*}=$ Mais de $10 \%$ de células imunorreativas; ${ }^{a}=$ resultado do teste do $\chi^{2}$; $b=$ resultado do teste exato de Fisher. 
imuno-histoquímico. Nos cortes seriados subseqüentes, igualmente foram obtidos três espécimes histológicos, um deles sempre corado pela $\mathrm{HE}$ e os demais dispostos em lâminas silanizadas, para eventual estudo imunohistoquímico complementar, caso surgissem áreas duvidosas nos cortes seriados corados pela HE. As lâminas não utilizadas foram enviadas ao arquivo, juntamente com os demais blocos de parafina do LS.

O exame imuno-histoquímico por citoqueratina foi realizado pela técnica da streptovidina-peroxidase, utilizando-se o anticorpo monoclonal primário AE1/ AE3 (Dakopatts), após recuperação antigênica com calor úmido. A reação foi considerada positiva quando ocorreu marcação de células no linfonodo, anotando-se número e tamanho dos focos epiteliais. Nos casos em que houve linfonodos adicionais retirados, os mesmos foram processados rotineiramente, com cortes transversais e inclusão da totalidade do linfonodo em parafina, com cortes histológicos corados pela HE.

\section{Resultados}

Após cortes aprofundados corados pela HE, não se observou a presença de macrometástases em nenhum dos LS. Foram detectadas metástases ocultas em 22 pacientes $(12,9 \%)$, sendo que em seis destas $(3,5 \%)$ o acometimento foi do tipo micrometástase e nas 16 restantes $(9,4 \%)$, de células tumorais isoladas. O número de LS dissecados não diferiu no grupo em que os mesmos se apresentavam livres ou acometidos por metástases ocultas. Nas demais 154 pacientes, os LS dissecados foram considerados negativos na avaliação por microscopia de luz em cortes corados pela HE.

No entanto, quando aplicada a técnica de imunohistoquímica para estes 154 casos, foi possível identificar metástases ocultas em 16 dos mesmos, sendo que em cinco se tratava de micrometástases e em 11 de células tumorais isoladas (Tabela 2). Igualmente, não se observou diferença em relação ao número de LS dissecados por paciente nos grupos em que o mesmo se encontrava livre ou comprometido. Com o emprego da imuno-histoquímica, teve-se ganho de $9,4 \%$ na identificação de micrometástases e de células tumorais isoladas.

Tabela 2 - Detecção de metástases ocultas em 170 linfonodos sentinelas por meio de diferentes métodos

\begin{tabular}{lcc}
\hline Métodos & $\begin{array}{c}\text { Células fumorais } \\
\text { isoladas }\end{array}$ & Micrometástase \\
\hline $\begin{array}{l}\text { Rotina (imprint intra- } \\
\text { operatório) }\end{array}$ & 0 & 0 \\
$\begin{array}{l}\text { Cortes seriados } \\
\text { (hematoxilina-eosina) }\end{array}$ & 0 & 6 \\
Imuno-histoquímica & 11 & 5 \\
Total & 11 & 11 \\
\hline
\end{tabular}

Não se constatou associação do tamanho do tumor, do tipo histológico e dos receptores de estrógeno, progesterona e HER 2 com a presença de micrometástases ou de células tumorais isoladas (Tabela 1). A distribuição percentual das medidas clínico-patológicas se apresenta estatisticamente a mesma entre os pacientes em que foram identificadas metástases e aqueles em que não foram $(p>0,05)$. No que se refere à diferenciação histológica, verificou-se que o número de tumores grau III foi maior que aqueles de graus I e II, contudo, não atingiu significância estatística $(\mathrm{p}=0,879)$.

\section{Discussão}

Embora as reais implicações decorrentes da presença de micrometástase e, sobretudo, de células tumorais isoladas nos LS sejam controversas, não há como ignorar a importância de adequado estudo anatomopatológico destes linfonodos no sentido de garantir taxas mínimas de falsos-negativos. Cabe assinalar, contudo, que a metodologia referente ao processamento anatomopatológico do LS, com a finalidade de fazer a detecção de metástases ocultas, ainda não se encontra bem estabelecida.

Tendo em vista que quanto mais exaustiva a avaliação do LS maior é a chance da detecção de metástases ocultas, utilizaram-se na metodologia do presente estudo cortes seriados e avaliação pela técnica de imuno-histoquímica.

No que se relaciona com o emprego de cortes seriados, corados pela técnica de $\mathrm{HE}$, verificou-se que no presente estudo esta metodologia proporcionou a detecção de micrometástases em seis casos, os quais se apresentaram negativos no exame intra-operatório. A relevância da realização de cortes seriados foi constatada em revisão feita por Dowlatshahi et al. ${ }^{7}$. As taxas de detecção de micrometástases e de células tumorais isoladas referidas nos estudos variaram entre 9 e $33 \%$, na dependência do número de cortes praticados.

Quanto ao uso da técnica de imuno-histoquímica, comprovou-se sua elevada acurácia na detecção de células tumorais isoladas e de micrometástases. O ganho obtido na detecção destas formas de células neoplásicas foi de $9,4 \%$. Os resultados apresentados no presente estudo são concordes com outros existentes na literatura. Em análise do LS de 214 pacientes, nas quais foram feitos cortes aprofundados, com intervalos de $100 \mu \mathrm{m}$, Weaver et al. ${ }^{9}$ constataram metástases ocultas em 19 dos mesmos, sendo que, em cinco, se tratava de micrometástases e em 14 de células tumorais isoladas. Utilizando cortes com intervalos de 50 $\mu \mathrm{m}$ (os menores) ou $100 \mu \mathrm{m}$ (os maiores), até esgotamento dos blocos, em série de 246 pacientes, Cserni ${ }^{10}$ observou a presença de micrometástases em nove das mesmas e células tumorais isoladas em outras nove. Em estudo de 476 LS, oriundos de 216 pacientes, nas quais realizaram 
três aprofundamentos corados por HE e estudo por imunohistoquímica, Klevesath et al. ${ }^{11}$ observaram que em nove das mesmas houve detecção de metástases ocultas, sendo que em quatro destas se tratavam de micrometástases e em cinco de células tumorais isoladas.

Em análise de 232 pacientes com LS comprometido por metástases ocultas, Colleoni et al. ${ }^{12}$ observaram correlação entre receptor de progesterona negativo, alto grau de diferenciação histológica e tamanho do tumor com a presença de células tumorais isoladas ou micrometástases. Conforme assinalado, não foram encontrados no presente estudo correlação estatisticamente significante entre as características anatomoclínicas dos tumores e a presença de células neoplásicas no LS.

Vários pesquisadores têm procurado verificar as taxas de comprometimento dos demais linfonodos axilares, nos casos em que o processamento diferido do LS demonstra a presença de micrometástases e de células tumorais isoladas.

Em estudo que envolveu 434 pacientes, nas quais o LS se apresentava envolvido por metástases ocultas, Viale et al. ${ }^{13}$ constataram que em 318 das mesmas $(73,3 \%)$ o comprometimento consistia em micrometástases e em $116(26,7 \%)$ em células tumorais isoladas. Avaliando os demais linfonodos axilares (linfonodos não sentinelas) de todas as pacientes, estes pesquisadores verificaram a presença de metástases em 68 pacientes do primeiro grupo
$(21,4 \%)$ e em $17(14,7 \%)$ daquelas em que existiam células tumorais isoladas no LS.

Em recente publicação, Houvenaeghel et al. ${ }^{14}$ reportaram suas observações acerca da prevalência de envolvimento de linfonodos axilares não sentinelas, em estudo de 488 pacientes com metástases ocultas em linfonodos sentinelas (301 com micrometástases e $187 \mathrm{com}$ células tumorais isoladas), encontrando envolvimento de linfonodos não sentinelas em 43 pacientes $(14,3 \%)$ com micrometástases em LS e em 30 (16\%) daquelas com células tumorais isoladas.

As conclusões destas investigações, no que se refere às taxas de comprometimento dos demais linfonodos axilares nos casos em que existem metástases ocultas no LS, reforçam a necessidade de se utilizar método de detecção das mesmas que apresente elevada acurácia. O exame imuno-histoquímico do LS demonstrou apresentar maior sensibilidade na identificação de micrometástases e de células tumorais isoladas quando comparado com a técnica de hematoxilina-eosina (HE). Em recente publicação, Holm et al. ${ }^{15}$ preconizaram o exame imunohistoquímico como rotina no intra-operatório. Em relação ao exame imuno-histoquímico diferido, os autores desta pesquisa acreditam que a relação custo-benefício é aceitável, porém quanto ao intra-operatório, por ser de custo muito elevado, sua prática ainda não ganhou aceitação em nosso médico.

\section{Referências}

1. Krag D, Weaver D, Ashikaga T, Moffat F, Klimberg VS, Shriver C, et al. The sentinel node in breast cancer-a multicenter validation study. N Engl J Med. 1998;339(14):941-6.

2. Veronesi U, Paganelli G, Viale G, Galimberti V, Luini A, Zurrida $S$, et al. Sentinel lymph node biopsy and axillary dissection in breast cancer: results in a large series. J Natl Cancer Inst. 1999;91(4):368-73.

3. Cody HS 3rd. Sentinel lymph node biopsy for breast cancer: does anybody not need one? Ann Surg Oncol. 2003;10(10):1131-2.

4. Piato JRM, Barros ACSD, Nisida ACT, Buchpigel CA, Barros N, Pinotti JA. Emprego concomitante da localização radioguiada da lesão e do estudo do linfonodo sentinela para o carcinoma invasor de mama não palpável. Rev Bras Ginecol Obstet. $2003 ; 25(9): 655-9$.

5. Veronesi U, Galimberti V, Mariani L, Gatti G, Paganelli G, Viale $G$, et al. Sentinel node biopsy in breast cancer: early results in 953 patients with negative sentinel node biopsy and no axillary dissection. Eur J Cancer. 2005;41 (2):231-7.

6. Naik AM, Fey J, Gemignani M, Heerdt A, Montgomery L, Petrek J, et al. The risk of axillary relapse after sentinel lymph node biopsy for breast cancer is comparable with that of axillary lymph node dissection: a follow-up study of 4008 procedures. Ann Surg. 2004;240(3):462-8.

7. Dowlatshahi K, Fan M, Snider HC, Habib FA. Lymph node micrometastases from breast carcinoma: reviewing the dilemma. Cancer. 1997;80(7): $1188-97$.

8. Sobin $\mathrm{LH}$, Wittekind $\mathrm{CH}$. TNM classification of malignant tumours. 6th ed. New York: Willey-Liss; 2002.

9. Weaver DL, Krag DN, Ashikaga T, Harlow SP, O'Connell M. Pathologic analysis of sentinel and nonsentinel lymph nodes in breast carcinoma: a multicenter study. Cancer. 2000;88(5): 1099-107.

10. Cserni G. Complete sectioning of axillary sentinel nodes in patients with breast cancer. Analysis of two different step sectioning and immunohistochemistry protocols in 246 patients. J Clin Pathol. 2002;55(12):926-31.

11. Klevesath MB, Bobrow LG, Pinder SE, Purushotham AD. The value of immunohistochemistry in sentinel lymph node histopathology in breast cancer. Br J Cancer. 2005;92(12):2201-5.

12. Colleoni M, Rotmensz N, Peruzzotti G, Maisonneuve P, Mazzarol $G$, Pruneri $G$, et al. Size of breast cancer metastases in axillary lymph nodes: clinical relevance of minimal lymph node involvement. J Clin Oncol. 2005;23(7):1379-89. 
13. Viale G, Maiorano E, Pruneri G, Mastropasqua MG, Valentini $S$, Galimberti V, et al. Predicting the risk for additional axillary metastases in patients with breast carcinoma and positive sentinel lymph node biopsy. Ann Surg. 2005;241(2): 319-25.

14. Houvenaeghel G, Nos C, Mignotte H, Classe JM, Giard S, Rouanet P, Lorca FP, Jacquemier J, Bardou VJ; Groupe des Chirurgiens de la Federation des Centres de Lutte Contre le Cancer. Micrometastases in sentinel lymph node in a multicentric study: predictive factors of nonsentinel lymph node involvement-Groupe des Chirurgiens de la Federation des Centres de Lutte Contre le Cancer. J Clin Oncol. 2006;24(12):1814-22.

15. Holm M, Paaschburg B, Balslev E, Axelsson CK, Willemoe GL, Flyger HL. Intraoperative immunohistochemistry staining of sentinel nodes in breast cancer: Clinical and economical implications. Breast. 2008; 17(4):372-5. 